\title{
Testemunhos orais e fotográficos: relatos de memórias das ações culturais do Mobral na comunidade sertaneja
}

\section{Oral and photographic testimonials: reports of memories of cultural actions of Mobral in the sertaneja community}

\author{
Jailson Costa da Silva* \\ Marinaide Lima de Queiroz Freitas**
}

\begin{abstract}
RESUMO
Este artigo é um recorte de uma pesquisa realizada no período de 2015 a 2018, no sertão de Alagoas, que teve como foco as ações desenvolvidas no Programa Mobral Cultural, implementado pelo Movimento Brasileiro de Alfabetização (Mobral), apoiando-se na História oral, Alberti (2008) e Bosi (1994), privilegiando como fontes as entrevistas e também a fotografia de Cartier-Bresson (1971), Guran (2011) e Leite (1993). Objetivou apresentar as narrativas memorialísticas advindas das fontes mencionadas de dois sujeitos inseridos no contexto das atividades culturais do referido Movimento, surgidas das indagações: A presença de ações culturais incentivadas pelo Mobral cultural ocasionou a valorização da cultura popular sertaneja? Quais os significados para os sertanejos das iniciativas culturais ofertadas? As fontes orais e visuais trouxeram novas reflexões em relação ao lugar - Sertão alagoano - e nos fizeram perceber as ressignificações que foram possíveis em um Movimento com a dimensão que teve o Mobral, na época da Ditadura Civil-militar.
\end{abstract}

Palavras-chave: Mobral Cultural. Oralidade. Fotografia. Sertão alagoano.

* Instituto Federal de Alagoas. Piranhas, Alagoas, Brasil. E-mail: jailsonsandes2009@gmail. com. http://orcid.org/0000-0001-5078-3603.

** Universidade Federal de Alagoas. Maceió, Alagoas, Brasil. E-mail: naide12@hotmail. com. http://orcid.org/0000-0003-3659-4165. 


\begin{abstract}
This article is a review of a research carried out in the period from 2015 to 2018, in the backlands of Alagoas, focused on the actions developed in the Mobral Cultural Program, implemented by the Brazilian Movement of Literacy (Mobral), based on oral history, Alberti (2008) and Bosi (1994), focusing on interviews as well as the photograph of Cartier-Bresson (1971), Guran (2011) and Leite (1993). It aimed to present the memorialistic narratives from the mentioned sources of two subjects inserted in the context of the cultural activities of such Movement, arising from the inquiries: the presence of cultural actions encouraged by the cultural Mobral caused the valorization of the sertaneja popular culture? What are the meanings for the sertanejos regarding the cultural initiatives offered? The oral and visual sources brought new reflections about the place - Sertão Alagoano - and it made us realize the resignifications that were possible in a Movement with the dimension that Mobral had, by the epoch of the Civil-Military Dictatorship.
\end{abstract}

Keywords: Cultural Mobral. Orality. Photography. Sertão Alagoano.

\title{
Considerações iniciais
}

Em pesquisa realizada no período de 2011 a 2013 sobre o impacto do Programa de Alfabetização Funcional (PAF), implantado pelo Movimento Brasileiro de Alfabetização (Mobral), na época da Ditadura Civil-militar ${ }^{1}$ no Brasil (1964-1985), constatamos que no âmbito do referido Movimento no sertão alagoano, especificamente, no município de Santana do Ipanema, muitas reflexões, ainda, permaneciam em aberto, tais como: a) A juvenilização presente nas turmas do Mobral; b) As iniciativas de profissionalização ofertadas pelo Mobral; c) A presença constante de ações culturais no município lócus da investigação quando da permanência dos sujeitos alfabetizandos, no PAF, no caso específico do sertão alagoano.

E nesse sentido, em 2015, dando continuidade às nossas investigações, optamos por estudar as ações culturais desenvolvidas pelo Mobral, conforme o item "c", acima referido, sem perder de vista outras investigações realizadas

1 No decorrer do texto, utilizamos o termo Ditadura Civil-militar, entendendo que o golpe de 1964 foi fruto de uma coalizão civil e militar. Confirmou-se com a ascensão de um novo bloco no poder que envolvia a articulação entre o conjunto das classes dominantes, a exemplo a burguesia industrial e financeira nacional e internacional, “[...] bem como uma camada (de caráter civil) de intelectuais e tecnocratas. $\mathrm{O}$ espectro de interesses representados por esse conjunto autoriza-nos a qualificá-lo como uma elite" (GERMANO, 2011, p. 17). 
por Freitas e Moura (2007), Amorim, Freitas e Moura (2009) e Silva (2013) que vêm buscando reconstruir a história da Educação de Jovens e Adultos (EJA) em Alagoas. Neste texto temos como objetivo apresentar as narrativas memorialísticas advindas de fontes orais e visuais de dois sujeitos, que vivenciaram as ações do Programa Mobral Cultural, desenvolvidas no Município de Santana do Ipanema ${ }^{2}$, lócus do nosso estudo. Ambos atuantes diretos, com participações diferenciadas. Um era artista local e o outro um ex-animador ${ }^{3}$ cultural, assim denominado. Nessa direção, problematizamos: A presença de ações culturais incentivadas pelo Mobral cultural ocasionou a valorização da cultura popular das comunidades sertanejas? Quais os significados para os sujeitos sertanejos das iniciativas culturais ofertadas pelo Mobral Cultural?

Nosso foco nas narrativas é oriundo dos postulados teóricos de Benjamin (2012) para quem, diferentemente da informação, que só tem valor enquanto é novidade, a narrativa "[...] não se esgota jamais. Ela conserva suas forças e depois de muito tempo ainda é capaz de desdobramentos" (p. 220). Isso porque as narrativas estão sob formas infinitas e estão presentes em todos os tempos, em todos os lugares, em todas as sociedades, inclusive no contexto de ditadura civil-militar, acontecida no Brasil, a partir do golpe de 1964.

Corroborando os escritos de Benjamin (2012), os estudos de Bosi (1994, p. 85) esclarecem o valor das narrativas ao dizer: "A arte da narração não está confinada nos livros, seu veio épico é oral. O narrador tira o que narra da própria experiência e a transforma em experiência dos que escutam”. É nessa perspectiva de respeito às experiências vividas e agora narradas que buscamos a composição de novas histórias sobre a atuação do Mobral Cultural, no sertão de Alagoas.

As narrativas que estamos construindo são tidas como fortes experiências humanas, que, nas palavras de Alves e Garcia (2008, p. 274), "[...] têm amplitude no tempo e no espaço. São narrativas encontradas que [permitiram] uma ressignificação, uma história diferente das que conhecemos em relação aos conhecimentos [...] políticos oficiais, que são, sobretudo, escritos", no caso específico, os conhecimentos do Mobral Cultural.

2 Situada na Mesorregião do Sertão Alagoano. De acordo com os dados do Instituto Brasileiro de Geografia e Estatística (IBGE, 2010) Santana do Ipanema conta com uma população de 44.932 habitantes, com área territorial de 437, $875 \mathrm{~km}^{2}$ e densidade demográfica de 102, 61 (hab. $\left./ \mathrm{km}^{2}\right)$. O Índice de Desenvolvimento Humano (IDHM) - Santana do Ipanema é 0,591, em 2010, o que situa esse município na faixa de Desenvolvimento Humano Baixo (IDHM entre 0,500 e 0,599) (ATLAS DO DESENVOLVIMENTO HUMANO NO BRASIL).

3 Optamos por apresentar apenas as vozes de dois interlocutores, considerando as dimensões reduzidas de um artigo. Salientamos que outros interlocutores participaram da pesquisa por meio de entrevistas a saber: cinco ex-supervisoras componentes da comissão estadual do Mobral, uma ex-supervisora de área do Município de Santana do Ipanema, e um ex-supervisor de área de um município vizinho, além dos ex-alunos do Mobral. 
Nessa trajetória, mais uma vez, a abordagem da história oral com base nos postulados teóricos de Alberti (2008) e Bosi (1994) foi o caminho percorrido articulando as fotografias, que são imagens narrativas, que, também, compuseram com as fontes orais que utilizamos. É importante dizer que o aparecimento das fotografias no momento das entrevistas ajudou-nos a perceber a necessidade dessa interação entre as fontes visuais - fotografias e as fontes orais - os depoimentos memorialísticos dos sujeitos que participaram do fato histórico.

Localizar as pessoas que atuaram no Mobral, fossem gestores da Coordenação Estadual (COEST), das Comissões Municipais (COMUN), bem como os sertanejos partícipes das atividades culturais do Mobral não foi tarefa fácil, pelo fato de estarmos pesquisando um Programa que tivera sua implantação no locus da pesquisa em 1973, ou seja, há mais de 40 anos. Essa condição levou-nos a seguir pistas como o caçador descrito por Carlo Ginzburg nos estudos sobre o paradigma indiciário, que se aventura pelas "[...] pistas mudas (se não imperceptíveis) deixadas pela presa [...].” (GINZBURG, 1989, p. 152). Assim, a partir de intenso movimento de idas e vindas ao campo de investigação, encontramos os interlocutores deste estudo. Dessa forma, podemos afirmar que o critério de escolha dos entrevistados foi aleatório.

Nas nossas pesquisas e neste recorte, também, a oralidade é utilizada como instrumento capaz de estabelecer uma relação entre a teoriaprática ${ }^{4}$, recorrendo à teoria da história para compreensão dos conceitos de história e memória e as formas como estas se relacionam. Na nossa trajetória de estudo, a história oral vem desempenhando um papel fundamental na reconstrução de fatos históricos, uma vez que nos permitiu: "[...] realizar entrevistas gravadas com pessoas que puderam testemunhar sobre acontecimentos, conjunturas, instituições, modos de vida ou outros aspectos da história contemporânea" (CPDOC, [2017?]) . Denominamos o tipo de entrevista que operamos de entrevista temática. Esse tipo de entrevista versa "[...] prioritariamente sobre a participação do entrevistado no tema escolhido" (ALBERTI, 2008, p. 175).

A restituição do passado por meio da memória, em nossos estudos, é sempre alvo de muito cuidado. Nesse sentido, aprendemos com Bosi (1994), a impossibilidade de resgate do passado, pois, para a autora, não é possível reviver o passado a partir da lembrança. É possível, apenas, a reconstrução e o repensar desse passado, tendo como base as ideias e imagens do presente. Nessa direção, a autora ressalta que "A lembrança é uma imagem construída pelos

4 Usamos os termos juntos para garantir a indissociabilidade existente entre eles.

5 Centro de Pesquisa e Documentação de História Contemporânea do Brasil (CPDOC). O que é história oral. Disponível em: http://cpdoc.fgv.br/acervo/historiaoral. Acesso em: 11 mar. 2019. 
materiais que estão, agora, à nossa disposição, no conjunto de representações que povoam nossa consciência atual" (BOSI, 1994, p. 55).

Merece destaque metodológico a interação das fontes orais com outras fontes - as fotografias -, na perspectiva da composição de uma rede documental, pois: "Na análise de entrevistas de História oral deve-se ter em mente também outras fontes - primárias e secundárias; orais, textuais, iconográficas etc. - sobre o assunto estudado" (grifos nossos) (ALBERTI, 2008, p. 187). É que a possibilidade de confrontar fontes variadas, como no caso dos sujeitos em estudo, contribuiu para o enriquecimento dos depoimentos e abriu possibilidade de comparação das informações contidas nas fontes orais com as demais, inclusive no processo de rememoração. Esse é um sentimento que vem permeando as nossas investigações e, no caso específico, no decorrer da entrevista.

O texto encontra-se na seguinte ordem: no item abaixo ocupamo-nos em apresentar, respectivamente, as fontes visuais, constituídas de narrativas que, interpretadas pelos pesquisadores, compõem novas histórias. Na sequência tecemos considerações acerca do Programa Mobral Cultural. No último item, dedicamo-nos a apresentar os interlocutores da pesquisa, destacando, em suas narrativas, pontos relacionados à importância das ações culturais do Mobral na vida dos sertanejos.

\section{A fotografia como fonte documental: alguns achados}

Os escritos de Cartier-Bresson (1971) traduzem o valor da fotografia no processo de reconstrução do passado, por meio da memória imagética que traz em sua essência fragmentos de um passado, que pode ser revisitado a partir da imagem. Dessa forma, pode-se entender que entre os meios de expressão existentes a fotografia sobressai-se, uma vez que "[...] é o único que fixa para sempre o instante preciso e transitório [...]" (CARTIER-BRESSON, 1971, p. 21). Trata-se da retenção de momentos que não voltam a acontecer, e que, por mais que fiquem gravados nas lembranças de quem os vivenciou não são possíveis de ser revelados, porque as memórias dos protagonistas da história não são reveláveis em laboratórios fotográficos.

Fixada na fotografia, a memória de um instante é preservada, guardada como um tesouro que carrega em si a preciosidade de um tempo que não se resgata, mas se reconstrói a partir das imagens, que evidenciam características de um acontecimento histórico e possibilitam o aguçamento da imaginação dos que não viveram tal momento; bem como, o reencontro de um passado presente 
nas lembranças dos sujeitos que protagonizaram o fato histórico. Nesta parte fazemos menção à história grafada nas fotografias, ao destacarmos as narrativas que as imagens carregam em si, e as muitas outras que podem ser imaginadas e interpretadas a partir delas; dessa forma, apoiamo-nos nos postulados teóricos de Cartier-Bresson (1971), Guran (2011) e Leite (1993).

Esse circuito social da fotografia vem nos possibilitando a percepção das mensagens presentes nas imagens e o contexto social de sua captação, uma vez que "[...] são resultado de um jogo de expressão e conteúdo que envolve, necessariamente, três componentes: o autor, o texto propriamente dito e um leitor" (MAUAD, 1996, p. 8). A imagem fotográfica, enquanto texto, vem nos permitindo novas interpretações do passado registrado pela câmera, que captura, a partir do olhar do fotógrafo, a imagem que lhe convém, que lhe chama mais a atenção.

As fontes orais, interagindo com as fontes visuais, registradas durante a atuação do Mobral em Alagoas, revelaram a intensidade do movimento na vida dos sertanejos. A fotografia funcionou como um instrumento de rememoração, pois, como destaca Guran (2011), “[e]stimulados pelas fotografias, os informantes vão muito além do que está representado na imagem, já que uma das características da fotografia é justamente esse poder de desencadear ideias recorrentes em um processo que tem tanto de sensível como de racional" (GURAN, 2011, p. 88). As conversas com as pessoas por meio de entrevistas possibilitaram o enriquecimento do diálogo, o que nos permitiu observar de perto as questões subjetivas nos testemunhos dos dois sujeitos, o que nos deu uma maior compreensão do que foi posto acerca dos fatos vividos, registrados nas fotografias.

Na trajetória de pesquisa sobre o Mobral de 2011 até 2016 conseguimos reunir um corpus documental composto por 87 fotografias $^{6}$, caracterizado por imagens diversas, que apresentam comportamentos fotográficos variados, em sua grande maioria de profissionais desconhecidos. Os estudos de Leite (1993, p. 165) mostram que essa categoria de imagens tem grande valor, uma vez que: "feita para recordar atos da vida, em sua continuidade, está carregada de conotações tanto mais fortes quanto mais condicionadas pelo mundo exterior", o que demonstrou o valor da memória na reconstrução da história da atuação do Programa Mobral Cultural em terras sertanejas.

6 Todas as fotografias fazem parte do conjunto de memórias do acervo pessoal dos entrevistados, e foram cedidas no momento das entrevistas e disponibilizadas para publicação. 


\section{Considerações sobre o Mobral Cultural}

No âmbito da educação de adultos, quando da ditadura civil-militar no Brasil, criou-se, em 1967, o Movimento Brasileiro de Alfabetização (Mobral) ${ }^{7}$, foi implementado em 1970 o Programa ${ }^{8}$ de Alfabetização Funcional (PAF), que perdurou até 1985. Segundo Fávero e Freitas (2011) esse Movimento teve o apoio integral dos governos autoritários, e, para compor a sua receita ${ }^{9}$, recebeu num primeiro momento quantias advindas da Loteria Esportiva, depois do Imposto de Renda de Pessoas Jurídicas ${ }^{10}$, o que para esses pesquisadores caracterizou-se como a Campanha mais ampla e mais rica existente no país.

O projeto da ditadura civil-militar passava pelo alargamento do avanço capitalista na constituição do país pela industrialização e, por isso mesmo, necessitava de mão de obra qualificada - o que incluía maior escolarização e redução do analfabetismo entre a mão de obra industrial -, para que atraísse multinacionais e que dessem conta de "retirar o Brasil do atraso histórico" a que estava submetido. Esse projeto passava, também, pela melhoria dos níveis de escolarização de jovens e adultos, historicamente interditados no direito à educação no país. O caminho primeiro, inegavelmente, era o de aprender a ler e escrever para que, deixando de serem analfabetos, homens e mulheres pudessem atender aos requisitos do capital e da mão de obra trabalhadora.

Havia, à época, forte motivação para criação do Movimento, que em nada se aproximava das múltiplas experiências de educação popular desenvolvidas nos anos iniciais da década de 1960, abortadas pela Ditadura civil-militar exatamente porque assumiam um compromisso emancipador da população pobre e de classes populares, principalmente no Nordeste do país.

É conveniente salientar que, antes do surgimento da grande campanha de alfabetização de adultos, denominada Mobral, contou-se com outra, que envolvia, além da alfabetização, como diz Paiva (2003), diferentes níveis de

7 O Mobral surgiu como Fundação amparada pela Lei n. 5.379 de 15 de dezembro de 1967.

8 Para se compreender a abrangência da proposta do Mobral, fez-se necessário mencionar os diversos programas implementados durante sua vigência. Apresentamo-los, mesmo de forma sucinta, com o intuito de demonstrar aos leitores que as ações do Mobral não se resumiram apenas à alfabetização como comumente é entendido: Programa de Alfabetização Funcional; o Programa de Educação Integrada; Programa Mobral Cultural; Programa de Profissionalização; Programa de Educação Comunitária para a Saúde; Programa Diversificado de Ação Comunitária; Programa de Autodidatismo.

9 O planejamento das ações do Movimento era baseado na receita que recebia.

10 Os contadores das empresas privadas eram visitados para a indicação de até $2 \%$ do Imposto de Renda. 
ensino, chamada Cruzada de Ação Básica Cristã (CABC). Conhecida como Cruzada $\mathrm{ABC}$, provinha de convênios estabelecidos entre o Ministério da Educação e Cultura e a United States Agency for International Development (MEC/ USAID) $)^{11}$. A Cruzada ABC teve sua origem a partir da iniciativa de "Um grupo de professores do colégio evangélico Agnes Erskine de Pernambuco que, em 1962, idealizou um trabalho de educação de adultos com sentido apostólico" (PAIVA, 2003, p. 299).

Foram reduzidas as ações de cultura popular por meio da repressão, e a Cruzada $\mathrm{ABC}$ apresentou-se com a função de legitimar as intenções do governo frente às classes populares, bem como ao grande contingente de pessoas analfabetas. Paiva (2003) ajuda a compreender as reais intencionalidades da Cruzada $\mathrm{ABC}$ ao destacar que ela também tinha os objetivos de:

Difundir uma imagem dos militares e dos norte-americanos, demonstrar o interesse dos governos brasileiro e norte-americano pela 'sorte do povo', inculcar nos participantes a convicção de que a ascensão social é possível e que ela depende fundamentalmente de esforço individual, supondo que isso contribuiria para minimizar as 'tensões sociais' na região (PAIVA, 2003, p. 346).

A legitimação das ações que estavam sendo desenvolvidas pelos militares frente à população brasileira era um ponto fundamental do regime que passara a vigorar a partir de 1964. Era necessário, nesse sentido, fazer a população acreditar também que os governantes estavam cumprindo o seu papel e que o crescimento do país dependia do desempenho da população. Portanto, cada indivíduo deveria se esforçar para alavancar o desenvolvimento da nação brasileira.

Já Scocuglia (2000, p. 153), ao tecer considerações acerca da alfabetização de adultos, realizada pela Cruzada $\mathrm{ABC}$, sobretudo no Nordeste, destaca que: "O apoio e a convergência de propósitos que os movimentos progressistas de alfabetização de adultos haviam encontrado no governo Goulart, a Cruzada $\mathrm{ABC}$ iria encontrar nos governos militares, na segunda metade dos anos 60".

Ressaltamos o fato de que a Cruzada $\mathrm{ABC}$ apresentava-se com a intenção de se contrapor às iniciativas pedagógicas implementadas pelas iniciativas de

11 Para Góes (1985, p. 33), esses convênios “cobriram todo o espectro da educação nacional, isto é, o ensino primário, médio e superior, a articulação entre os diversos níveis, o treinamento de professores e a produção e veiculação de livros didáticos". 
alfabetização de adultos que antecederam o Regime Militar, e por isso suas ações receberiam, evidentemente, total apoio e adesão do governo militar.

Como a Cruzada ABC era uma campanha de base nordestina, Paiva (2003) enfoca que, em 1969, exigia-se a sua nacionalização. Em outras palavras, a ideia era que a Cruzada $\mathrm{ABC}$ se transformasse em um movimento de alfabetização "brasileiro". Esse processo de transição "[...] dá conta da liquidação da Cruzada $\mathrm{ABC}$ e lança as bases para um programa nacional executado pelo próprio Mobral a partir do ano seguinte" (PAIVA, 2003, p. 346).

Em seus estudos sobre o surgimento do Mobral, Paiva (2003) destaca que a sua intencionalidade passava pelo Plano de Alfabetização e Educação Continuada de Adultos, que fora elaborado pelo Departamento Nacional de Educação (DNE). Uma vez que o projeto de criação do Movimento era um anexo do referido Plano que estabelecia entre suas diretrizes a alfabetização de adultos vinculada às prioridades econômicas e sociais e às necessidades presentes e futuras de mão de obra.

Já o Mobral Cultural teve seu lançamento em 1973 na perspectiva de educação permanente que o Movimento defendia, voltado para o desenvolvimento de ações culturais, e procurava envolver os mobralenses advindos do PAF e de outra iniciativa denominada Programa de Educação Integrada (PEI) ${ }^{12}$. Havia o entendimento de que a atuação dessas pessoas não deveria limitar-se à sala de aula. Buscava, com isso, a integração dos que passaram pelo processo de alfabetização e na continuidade dos estudos; bem como a comunidade em geral, a partir da valorização das expressões culturais que estes sujeitos possuíam. Concebia a ação cultural como "complementação da ação pedagógica, preenchimento sadio das horas de lazer e valorização ou descoberta das potencialidades criativas do homem" (CORRÊA, 1979, p. 241-242).

Explica Paiva (2003, p. 382) que os programas do Mobral foram estratégias de sobrevivência institucional do órgão, que encontrava legitimidade e autonomia na vigência dos governos autoritários: "Um grande sistema de educação permanente a serviço da segurança interna do regime e do sistema de dominação era a grande tarefa do Mobral".

As ações do Mobral Cultural norteavam-se nos princípios de "democratização" da cultura, dinamização da criatividade e intercâmbio cultural e valorização do homem e da cultura local (CORRÊA, 1979). Sua estrutura operacional funcionava em três níveis de atuação: nacional, estadual e municipal

12 O PEI tinha a duração de 12 meses e correspondia às quatro primeiras séries do então ensino de $1^{\circ}$ grau. A relevância da sua implementação dava-se considerando que aprender a ler não era suficiente para o aluno, no sentido de "Identificar, pela memória" (FARIA, [1977?], p. 40). 
e desenvolvia suas atividades por meio de duas unidades operacionais: o Posto Cultural e a Mobralteca ${ }^{13}$.

\section{Narrativas do animador das ações culturais}

A mobilização das comunidades ${ }^{14}$ para a participação nos programas de atividades culturais do Mobral contava com a figura de um animador. A coordenação estadual de Alagoas, nessa função, contava com o jovem e comunicativo José Petrúcio de Oliveira Silva. Essa função era caracterizada como uma espécie de apresentador, ou o que se se convencionou chamar de mestre de cerimônias.

$\mathrm{O}$ animador das atividades culturais era a pessoa responsável, em campo, pela concretização dos trabalhos desenvolvidos quando das visitas da Mobralteca; bem como da mobilização das comunidades rurais, valendo-se da Minimobralteca ${ }^{15}$, que, por ser um automóvel compacto, conseguia chegar às comunidades mais longínquas.

O interlocutor falou-nos do trabalho que desenvolveu durante nove anos e oito meses de atuação no Mobral, cujo início deu-se como motorista; e destacou com muita lucidez os trabalhos realizados em todos os municípios do estado, no âmbito do programa de atividades culturais.

No momento da entrevista tivemos acesso às fotografias de que o informante dispunha em seus arquivos pessoais. Pudemos visualizar por meio de 27 delas o cotidiano da realização das atividades culturais no interior do estado. Essas fotografias foram imediatamente disponibilizadas para nós e algumas aparecem no decorrer deste artigo.

O depoente enfatizou a importância da Minimobralteca para se alcançar as comunidades mais isoladas. Por ser um carro menor, ele conseguia chegar em localidades consideradas de difícil acesso, como demonstra a foto a seguir

13 As Mobraltecas eram caminhões equipados com videocassete, receptor de televisão, projetor de cinema, livros, pinacoteca, material de artesanato, palco desmontável - onde o animador da Mobralteca promovia um verdadeiro 'show' de cultura e conseguia a adesão e amparo de todos os talentos locais.

14 Referimo-nos a comunidades, considerando que o mesmo animador atuava nas demais cidades do sertão alagoano.

15 A Minimobralteca surgiu da necessidade de se atingir maior interiorização do programa de desenvolvimento cultural. "Pode-se caracterizar a Minimobralteca como uma unidade reduzida da Mobralteca caminhonete, pick-up ou mesmo um pequeno barco" (MOBRAL, 1982, p. 7). Em Alagoas o veículo adaptado para essa função fora uma perua Kombi. 
(Figura 1), na qual a Minimobralteca aparece na realização de um evento em uma das muitas comunidades rurais do sertão alagoano.

\section{FIGURA 1 - APRESENTAÇÕES CULTURAIS COM A UTILIZAÇÃO DA MINIMOBRALTECA}

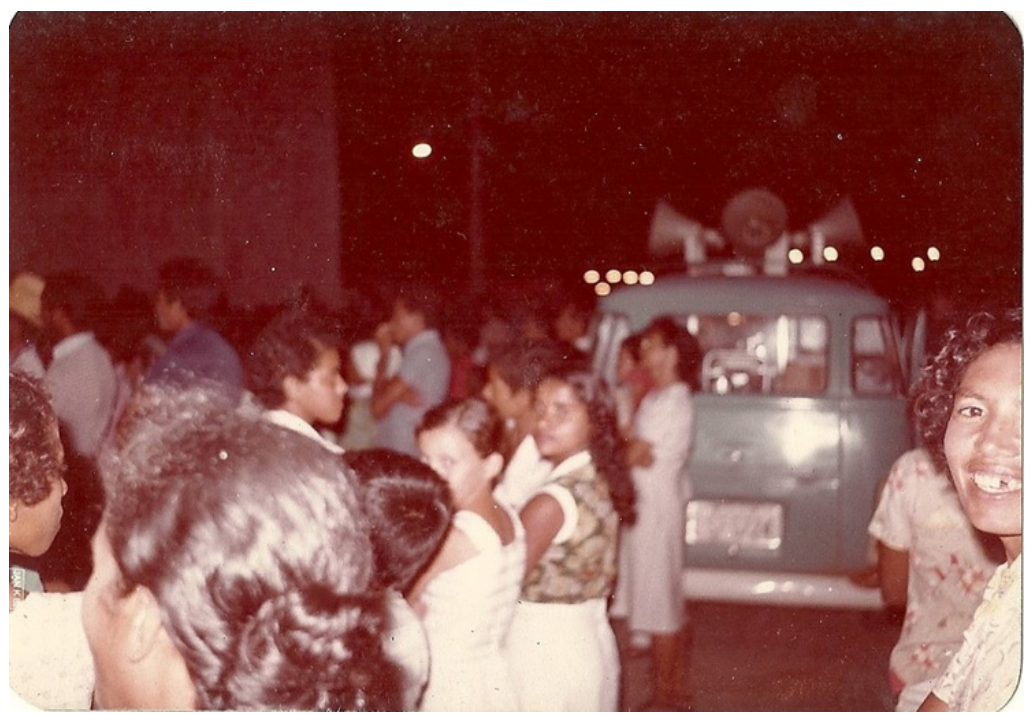

FONTE: Arquivo pessoal de José Petrúcio de Oliveira Silva.

Diante da fotografia, emocionado, José Petrúcio narrou:

Quem chegava lá no sítio, no interiorzão mesmo era a Minimobralteca. A Minimobralteca era uma Kombi né? Uma Kombi. Kombi adaptada, com gerador, com teatro de boneco. Eu me lembro também que a gente manuseava os fantoches [...] televisão também tinha! Além do projetor de filmes [...] a gente tinha tudo! O básico, além de também, a gente chamava de Baú da criatividade, era o material de pintura [...] que as pessoas pintavam, do jeito que queria; tricô, linhas, a gente levava tudo, eles passavam o dia todo mexendo naquelas coisas, inventavam coisas, era assim (JOSÉ PETRÚCIO DE OLIVEIRA SILVA).

A chegada das ações culturais às comunidades mais isoladas do sertão alagoano possibilitava a socialização da produção cultural do país e das in- 
formações que só chegavam a esses lugares por meio das ondas do rádio. É importante enfatizar que as "vocações culturais" de cada comunidade também tinham espaço nos encontros organizados pelo movimento, como nos disse o ex-animador:

No dia que a Mobralteca chegava os alunos vinham todos. A noticia se espalhava o boca-a-boca era rápido, o poder também do som ia até distante, eles escutavam. Comunidades vizinhas escutavam o barulho e iam, porque antes da gente parar eu entrava com o gerador ligado e saia chamando, fazendo o chamamento que ia acontecer em tal lugar, [...]. A $i$ era geral cara! Em cada atividade dessa juntava muita gente [...] 300, 500, 1.000 pessoas 2.000 pessoas, gente muita gente! (JOSÉ PETRÚCIO DE OLIVEIRA SILVA).

Os eventos contavam com a apresentação da cultura dos artistas locais, que se destacavam na música, no artesanato entre outros; apresentavam-se, também, grupos de folguedos tradicionais da região. Entendemos que esses acontecimentos foram imprescindíveis no reconhecimento da cultura dos sujeitos ordinários, apresentados nos estudos de Certeau (2011), a partir das seguintes características:

Produtores desconhecidos, poetas de seus negócios, inventores de trilhas nas selvas da racionalidade funcionalista, [...]. Traçam 'trajetórias indeterminadas', aparentemente desprovidas de sentido porque não são coerentes com o espaço construído, escrito e pré-fabricado onde se movimentam. São frases imprevisíveis num lugar ordenado pelas técnicas organizadoras de sistemas (CERTEAU, 2011, p. 91).

São os sujeitos anônimos, que em suas trajetórias culturais reinventam, por meio de táticas, novas maneiras de viver no mundo marcado pelo poder, escapando das determinações dos lugares que lhes são impostos, e transformam esses lugares em espaços, que por eles ocupados ganham novos sentidos. Assim os autores Certeau e Giard (2013) e Certeau (2011) definem a constituição desses sujeitos em suas especificidades, levando-nos a compreender a relevância da percepção dessas peculiaridades. Os autores são enfáticos ao esclarecerem que essa cultura dos sujeitos ordinários carrega em si 
[...] uma diversidade fundamental de situações, interesses e contextos, sob a repetição aparente dos objetos de que se serve. A pluralização nasce do uso ordinário, daquela reserva imensa construída pelo número e pela multiplicidade das diferenças (CERTEAU; GIARD, 2013, p. 340).

A imagem a seguir (Figura 2) desvela o que o interlocutor caracterizou como uma festa que conseguia mobilizar as pessoas da comunidade e não apenas os alunos do Mobral.

\section{FIGURA 2 - APRESENTAÇÕES CULTURAIS: QUADRILHA - MATA GRANDE ${ }^{16}$, JULHO DE 1982}

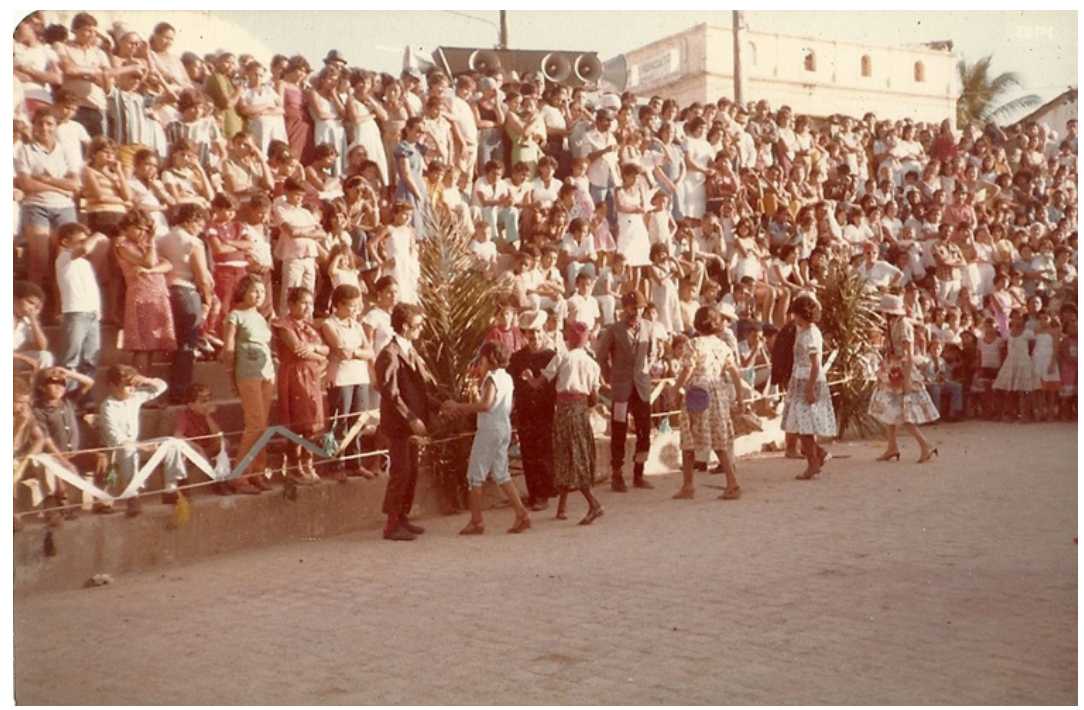

FONTE: Arquivo pessoal de José Petrúcio de Oliveira Silva.

A fotografia como “[...] um espelho de momentos passados" (LEITE, 1993, p. 160) proporciona mensagens que retratam as pessoas que se aglomeravam para celebrar a cultura. Corroboramos as narrativas do depoente, pois a imagem nos permitiu, mesmo inferindo, interpretar os significados das atividades culturais para o povo sertanejo, que recebia as ações com muito entusiasmo.

16 Situada na Mesorregião do Sertão Alagoano. De acordo com os dados do Instituto Brasileiro de Geografia e Estatística (IBGE, 2010). Mata Grande conta com uma população de 24.698 habitantes, com área territorial de $910,37 \mathrm{~km}^{2}$ e densidade demográfica de $27,13 \mathrm{hab} . / \mathrm{km}^{2}$ (ATLAS DO DESENVOLVIMENTO HUMANO NO BRASIL, 2013). 
Acreditamos que as pessoas se aglomeravam para participar das manifestações culturais, para além da submissão ao Programa pois encontravam sentido no que vivenciavam. Nas palavras de Certeau (2011, p. 39), esses sujeitos não devem ser tidos apenas como consumidores, mas como usuários ativos das ações que lhes eram dadas. Faziam das "[...] representações ou leis que lhes eram impostas outra coisa que não aquela que o conquistador julgava obter por elas".

Essa perspectiva certeauniana afasta a representação dos sertanejos enquanto sujeitos passivos. $\mathrm{O}$ autor contribuiu para que nós rompêssemos com o estigma da alienação, visto que esses sujeitos têm condições de subverter as imposições, "[...] não rejeitando-as diretamente, ou modificando-as, mas pela sua maneira de usá-las para fins [...]" (CERTEAU, 2011, p. 39). Essas novas maneiras de uso aparecem nas vozes dos nossos interlocutores, ao narrarem a mobilização que era feita pelos próprios artistas da terra, que aproveitavam o momento para a divulgação dos seus trabalhos.

\section{Lembranças do seguidor da Mobralteca}

Neste tópico o espaço é reservado para as narrativas de um sertanejo que vivenciou de perto as atividades realizadas na Mobralteca, que, no início de sua carreira, em terras do sertão alagoano, caracterizou-se como seu primeiro palco, considerando ser uma apresentação para o grande público.

Seguindo as trilhas deixadas pelo Mobral Cultural no sertão alagoano, saímos de Santana do Ipanema e chegamos à cidade vizinha de Olho D'água das Flores ${ }^{17}$. Nesse processo de incursão, encontramo-nos com o Sr. Edgard de Lima, cantor profissional, e reconhecido em toda a região sertaneja, por seu estilo musical peculiar. Essa entrevista fora marcada pelo entusiasmo do depoente em socializar as suas experiências adquiridas nos palcos da Mobralteca em suas passagens pela comunidade sertaneja.

O narrador, que ainda permanece como cantor profissional e proprietário de um estabelecimento comercial na referida cidade, revelou que o despertar para a carreira artística deu-se a partir do aparecimento do caminhão itinerante que visitava as cidades do sertão e valorizava os talentos locais. Por ser uma

17 Município da Mesorregião Sertão Alagoano, situada na Microrregião de Batalha com Área 183,96 km² e uma População de 20.364 hab. (Censo 2010). O Índice de Desenvolvimento Humano (IDHM) - Olho D’Água das Flores era 0,565, em 2010, o que situa esse município na faixa de Desenvolvimento Humano Baixo (IDHM entre 0,500 e 0,599) (ATLAS DO DESENVOLVIMENTO HUMANO NO BRASIL). 
pessoa interessada pela música, à época, já tocava violão e animava as festas e encontros entre amigos. O Sr. Edgard Lima, no entanto, encontrou na Mobralteca a oportunidade de superação dos limites da timidez e a oportunidade de iniciação da carreira profissional. Ele nos disse:

[...] na época foi muito importante pra mim pra minha carreira inclusive, por que como eu falei antes, se não fosse a Mobralteca eu não seria cantor profissional hoje, porque foi ela quem me incentivou, me fez descobrir o talento que eu tinha, e que eu não sabia. Que foi se desenvolvendo através da Mobralteca, que me deu a oportunidade de mostrar o meu talento e as pessoas incentivarem depois. E eu botei isso na cabeça e hoje [2016] sou cantor e compositor. Eu agradeço primeiramente a Deus e à Mobralteca que na época deu essa oportunidade não só a mim, como a outras pessoas, outros artistas da terra, portanto posso me considerar um filho dela, eu me considero um filho da Mobralteca (EDGARD LIMA).

A frase utilizada pelo depoente, "[e] u agradeço primeiramente a Deus [...]", vem marcada pelos valores e usos religiosos e traz no nosso entendimento certa submissão e obediência ao discurso oficial que criou o Mobral. Além de existir um sentido de que a providência divina fez com que o Movimento chegasse ao sertão. Ele não percebera que a função da Mobralteca era incentivar os chamados talentos locais. E, para isso, de forma sistemática fazia visitas por meio do caminhão que se transformava em palco artístico com cenários atraentes nos municípios sertanejos.

É de se ressaltar que muitos talentos foram descobertos e muitos artistas como o Sr. Edgar começaram a acompanhar o caminhão em apresentações em outros municípios e estados. O interlocutor revelou que, depois da sua primeira apresentação em seu município de origem, fora convidado a apresentar-se em outras cidades por onde a Mobralteca passava, o que lhe rendeu o título de "seguidor da Mobralteca".

Segundo os interlocutores, a estadia da Mobralteca em municípios do sertão alagoano representava a possibilidade de apresentação dos trabalhos de artistas que já tinham um certo reconhecimento. Bem como o incentivo àqueles que, com muita timidez, esboçavam o desejo de seguir a carreira artística. Muitos desses não tinham sequer o instrumento musical, e utilizavam os que eram disponibilizados na Mobralteca.

A fotografia a seguir (Figura 3) trata, no dizer do ex-animador de atividades culturais - sujeito que aparece na imagem segurando o microfone - de uma 
das muitas iniciativas que o Mobral Cultural desenvolvia nas festas dos santos padroeiros, assim como em outras festividades dos municípios do interior do estado de Alagoas onde atuava. Inclua-se nesse contexto a cidade de Santana do Ipanema, locus desse estudo, onde todo mês de julho acontece a festa da Senhora Sant'Ana, evento que permanece muito concorrido no sertão alagoano.

FIGURA 3 - FESTA DO PADROEIRO

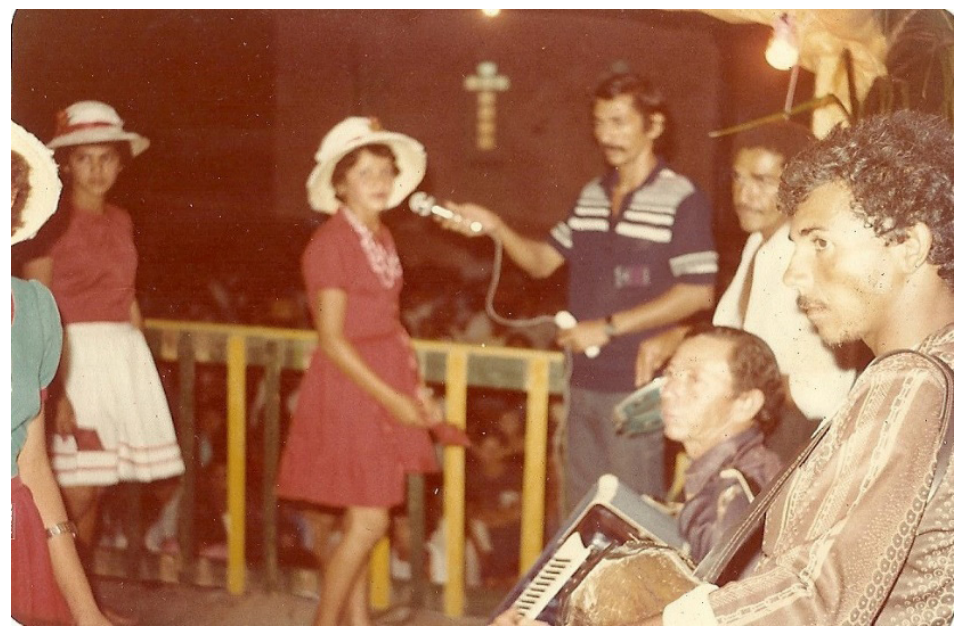

FONTE: Arquivo pessoal de José Petrúcio de Oliveira Silva.

A cena fotografada acima registra um dos momentos de confraternização em louvor ao santo patrono de uma cidade do sertão, em que a memória do interlocutor não permitiu a identificação daquela localidade. Observa-se na imagem um palanque de madeira, armado na praça central onde músicos e grupos de dança, em troca de saberes, apresentavam-se e animavam a noite da multidão que os acompanhava. Constituía-se um ritual de cultura popular com múltiplas trocas materiais e simbólicas, perceptíveis aos nossos olhos, ao mostrar que, em festas como as realizadas pelo Mobral Cultural e na participação nos folguedos, os participantes - homens e mulheres - aprenderam a socializar e trocar seus bens, serviços e significados.

A partir das narrativas presentes nas fontes orais e nas fontes visuais, conseguimos compreender as ressignificações das práticas ordinárias, cotidianas recorrentes na região sertaneja, e tomamos como âncoras as duas categorias destacadas por Certeau (2011) - estratégia e tática - que permeiam os contextos sociais nos quais os sujeitos constroem suas vivências. Ao fazer a 
distinção entre essas duas categorias, Certeau nos ensina que “[...] as estratégias apontam para a resistência que é o estabelecimento de um lugar [...]; as táticas apontam para uma hábil utilização do tempo, das ocasiões que apresenta [...] (CERTEAU, 2011, p. 96).

As resistências apontadas pelas estratégias estão relacionadas à manipulação das relações de poder instituídas pela ordem social, enquanto as táticas são caracterizadas como armas dos homens ordinários que encontram meios de ressignificação das imposições que sofrem. E buscam, por meio das trajetórias táticas, novos sentidos que os mantêm ativos enquanto sujeitos, capazes de perceber a fragilidade da ordem para atacar ou burlar a estrutura.

Destacamos a relevância da apresentação das outras dimensões da história, presentes nos testemunhos dos nossos interlocutores, ao darmos visibilidade às narrativas desses sujeitos que não participaram da construção da história oficial. Tomamos como base os escritos de Benjamin que demonstram preocupação com as microrrealidades, sempre na perspectiva de rompimento com a linearidade da história. Destacamos a "[...] tarefa de escovar a história a contrapelo" (BENJAMIN, 2012, p. 245).

A partir das narrativas do Sr. Edgard de Lima percebemos que as influências socializantes são de fato heterogêneas, uma vez que, como afirmou, desde muito jovem já tocava violão e cantava em festas com os amigos. A Mobralteca ajudou-o na ampliação, proporcionando-lhe novas influências socializantes, que no seu dizer foram fundamentais para seu crescimento profissional. O excerto a seguir ilustra bem essa situação:

E aí com isso comecei a pensar, e achar que podia ser um cantor futuramente, mas mesmo assim como eu sabia que era muito dificil de ser um cantor profissional, comecei a cantar em barzinho, em festinha e fui me destacando, me destacando e o caminho foi terminar gravando um disco. Logo após que eu gravei esse disco virei profissional, não quis parar de gravar mais, e o povo me chama de cantor. Em 1982 eu gravei o primeiro disco, um compacto duplo, na época era de vinil, e de lá para cá eu venho gravando [...] hoje nós temos $10 \mathrm{CDs}$, temos três LPs de Vinil, um compacto e dois DVDs. Ai eu virei artista de verdade, profissionalmente falando! Já sou conhecido a nivel nacional, através da Rede Record, através de outras redes [...] SBT, fiz alguns programas de televisão a nivel nacional, na TV Diário de Fortaleza e outros e outros [...] e o Edgard Lima hoje é um nome [...] não é sucesso nacional porque não é fácil isso! (EDGARD LIMA). 
O interlocutor atribui o êxito de sua carreira ao aparecimento da Mobralteca nos municípios do sertão alagoano. Apesar de já ter o talento para a música, ele insiste em dizer que sua carreira só foi alavancada a partir da oportunidade que apareceu no sertão na década de 1970. Na entrevista ele deixou transparecer um sentimento de gratidão às iniciativas que eram desenvolvidas pelo "governo federal da época". Seu envolvimento com a Mobralteca foi tão intenso que ele chegou a acompanhar o caminhão itinerante em outros estados do Nordeste.

\section{Considerações finais}

Compreendemos os sujeitos sertanejos enquanto sujeitos ordinários e praticantes (CERTEAU, 2011), e buscamos narrar no decorrer do texto a maneira como os depoentes que participaram das ações do Mobral Cultural interpretaram e lidaram com as informações doadas/impostas pelo Movimento em questão, naquele contexto de ditadura, que por sua vez representava um poder ideológico do campo das estratégias.

Seguimos o nosso objetivo de apresentar para os leitores/leitoras as narrativas memorialísticas de dois sujeitos inseridos no município em foco e no contexto das atividades culturais do referido Movimento, apresentamos outros olhares acerca da história do sertão e dos sujeitos sertanejos, e rompemos com os estigmas criados e veiculados na história oficial.

As entrevistas e as imagens utilizadas como fontes constituíram narrativas que demonstram como os sertanejos recriaram e reconstruíram sentidos em suas culturas, segundo suas possibilidades de atuação no mundo, e fizeram-se sujeitos a partir das experiências vividas. Permitiram, também, possíveis "respostas" às questões levantadas neste estudo, a dar visibilidade, por meio da história oral, à memória dos sertanejos que participaram das ações culturais do Mobral.

No sertão de Alagoas e diante da complexidade de significados, as narrativas orais e visuais revelaram que o Mobral Cultural levantava inicialmente as práticas culturais existentes nas comunidades sertanejas. O mesmo acontecia em outros espaços do Brasil onde atuava, socializando-as de forma organizada, e constituía grandes atividades realizadas em praças das cidades e vilarejos, por meio das unidades operacionais Posto Cultural, Mobralteca e Minimobralteca, ao apresentar talentos locais, fossem na música, no artesanato ou outras práticas até então invisibilizadas.

Destacamos, ainda, a valorização e o reconhecimento dos artistas locais, sobretudo músicos que encontraram nos palcos da Mobralteca as oportunida- 
des de mostrar seus trabalhos e iniciar carreiras profissionais pela mobilidade conferida aos artistas, que criavam coragem para se apresentar nos municípios circunvizinhos e em outros estados do Nordeste. Foi este o caso de um de nossos interlocutores que se autodenominou seguidor da Mobralteca. Segundo os interlocutores, a interação entre esses talentos possibilitava o brilhantismo da festa que conseguia reunir artistas da redondeza, muitos deles, naquele contexto, ainda anônimos.

Diante dessas oportunidades, em um lugar carente como o sertão alagoano, as narrativas dos sujeitos, na rememoração de suas experiências, expressaram uma forte aceitação do Mobral. Suas falas foram sempre acompanhadas de saudosismo sobre as contribuições advindas das ações do Programa Cultural, e de outras implementadas pelo Movimento nas décadas de 1970 e 1980 sem, no entanto, as situarem no contexto da ditadura civil-militar, em plena vigência à época.

Este artigo teve sua relevância na necessidade de recriação das ações do Programa Mobral Cultural no sertão alagoano, a partir da tessitura das histórias e memórias de sujeitos sertanejos, sobre como experienciaram e ressignificaram as ações culturais desenvolvidas pelo Mobral no contexto da ditadura civil-militar. Ressignificação entendida como "maneiras de fazer" que, nas palavras de Certeau (2011, p. 41), “[...] constituem as mil práticas pelas quais usuários se reapropriam do espaço organizado pelas técnicas de produção sociocultural", ou seja, os sentidos atribuídos em suas próprias culturas às ações apresentadas pelo Programa Mobral Cultural na comunidade sertaneja.

\section{REFERÊNCIAS}

ALBERTI, Verena. Histórias dentro da história. In: PINSKY, Carla B. (Org.). Fontes históricas. São Paulo: Contexto, 2008. p. 155-202.

AMORIM, Maria Gorete; FREITAS, Marinaide Lima de Queiroz; MOURA, Tânia Maria de Melo. Educação de Jovens e Adultos em Alagoas: uma releitura das políticas e ações em âmbito governamental nas décadas de 1990 a 2000. In: AGUIAR, Maria Ângela da Silva et al. (Orgs.). Educação e diversidade: estudos e pesquisas. Recife: Gráfica J. L. Vasconcelos, 2009. p. 145-170.

ALVES, Nilda; GARCIA, Regina Leite. Prefácio - Continuando a conversa. In: FERRAÇO, Carlos Eduardo; PEREZ, Carmem Lúcia Vidal; OLIVEIRA, Inês Barbosa de Oliveira (Orgs.). Aprendizagens cotidianas com pesquisa - novas reflexões em pesquisa nos/dos/com os cotidianos das escolas. Petrópolis: DP et Alii, 2008. 
ATLAS DO DESENVOLVIMENTO HUMANO NO BRASIL. Rio de Janeiro: PNUD, IPEA, Fundação João Pinheiro. Disponível em: http://www.atlasbrasil.org.br/2013/pt/. Acesso em: 04 mar. 2017.

BENJAMIN, Walter. Magia e técnica, arte e politica: ensaios sobre literatura e história da escrita. 8. ed. São Paulo: Brasiliense, 2012. (Obras Escolhidas v.1).

BOSI, Ecléa. Memória e sociedade: lembranças de velhos. 3. ed. São Paulo: Companhia das Letras, 1994.

CARTIER-BRESSON, Henri. “O momento decisivo”. In: BACELLAR, Mário Clark (Org.). Fotografia e jornalismo. São Paulo: Escola de Comunicações e Artes (USP), 1971. p. 19-26.

CERTEAU, Michel. A invenção do cotidiano: artes de fazer. 17. ed. Petrópolis: Vozes, 2011.

CERTEAU, Michel; GIARD, Luce. Uma ciência prática do singular. In: CERTEAU, Michel; GIARD, Luce; MAYOL, Pierre (Orgs.). A invenção do cotidiano: 2 Morar, cozinhar. 12. ed. Petrópolis: Vozes, 2013.

CORRÊA, Arlindo Lopes. Educação de massa e ação comunitária. Rio de Janeiro: AGGS/Mobral, 1979.

CPDOC. Centro de Pesquisa e Documentação de História Contemporânea do Brasil. O que é história oral. [2017?]. Disponível em: http://cpdoc.fgv.br/acervo/historiaoral. Acesso em: 11 mar. 2019.

FARIA, Gustavo de. Soletre Mobral e leia Brasil. Sete anos de luta pela alfabetização. Rio de Janeiro: Ministério da Educação e Cultura; Guavira Editores. [1977?].

FÁVERO, Osmar; FREITAS, Marinaide Lima de Queiroz. Educação de jovens e adultos: um olhar sobre o passado e o presente. Inter-ação. Revista da Faculdade de Educação, Goiânia, v. 36, 2011.

FREITAS, Marinaide Lima de Queiroz; MOURA, Tânia Maria de Melo. A Educação de Jovens e Adultos em Alagoas: incursões na história das - ações e concepções em âmbito governamental (1960-1980). In: GRACINDO, Regina Vinhaes et al. (Org.). Educação como exercício de diversidade: estudos em campos de desigualdades socioeducacionais. Brasília: Liber Livro, 2007.

GERMANO. José Willington. Estado militar e educação no Brasil (1964-1985). 5. ed. São Paulo: Cortez, 2011.

GINZBURG, Carlo. Mitos, emblemas, sinais: morfologia e história. São Paulo: Companhia da Letras, 1989.

GÓES, Moacyr de. Voz Ativa. In: CUNHA, Luiz Antônio; GÓES, Moacyr de (Orgs.). O golpe na educação. Rio de Janeiro: Jorge Zahar, 1985. 
GURAN, Milton. Considerações sobre a constituição e a utilização de um corpus fotográfico na pesquisa antropológica. Discursos Fotográficos, Londrina, v. 7, n. 10, p. 77-106, jan./jun. 2011.

LEITE, Miriam Moreira. Retratos de família. São Paulo: Edusp, 1993.

MAUAD, Ana Maria. Através da imagem: fotografia e história interfaces. Tempo, Rio de Janeiro, v. 1, n. 2, p. 73-98, 1996.

MOBRAL. Movimento Brasileiro de Alfabetização. O programa desenvolvimento cultural. DEPEC/DIDEC, maio, 1982.

PAIVA, Vanilda. História da educação popular no Brasil: educação popular e educação de adultos. 6. ed. São Paulo: Edições Loyola, 2003.

SCOCUGLIA, Afonso Celso. Histórias inéditas da educação popular: do sistema Paulo Freire aos IPM da ditadura. João Pessoa: Editora Universitária: UFPB; São Paulo: Cortez, 2000.

SILVA, Jailson Costa da. O Mobral no sertão alagoano: das histórias e memórias às sínteses possíveis após quatro décadas. 2013. 153 f. Dissertação (Mestrado em Educação) - Centro de Educação, Programa de Pós-Graduação em Educação, Universidade Federal de Alagoas. Maceió, 2013.

Texto recebido em 04/06/2019.

Texto aprovado em 11/09/2019. 